\title{
Role of Dopaminergic Receptors Within the Ventral Tegmental Area in Antinociception Induced by Chemical Stimulation of the Lateral Hypothalamus in an Animal Model of Orofacial Pain
}

This article was published in the following Dove Press journal:

Journal of Pain Research

\author{
Tina Matini ${ }^{1}$ \\ Amir Haghparast $\mathbb{D}^{\prime}$ \\ Laleh Rezaee ${ }^{2}$ \\ Sakineh Salehi (D) $^{2,3}$ \\ Azita Tehranchi ${ }^{4}$ \\ Abbas Haghparast $\mathbb{D}^{2}$ \\ 'School of Dentistry, International \\ Branch of Shahid Beheshti University of \\ Medical Sciences, Tehran, Iran; \\ ${ }^{2}$ Neuroscience Research Center, School \\ of Medicine, Shahid Beheshti University \\ of Medical Sciences, Tehran, Iran; \\ ${ }^{3}$ Department of Medicine, Ardabil \\ Medical Sciences Branch, Islamic Azad \\ University, Ardabil, Iran; ${ }^{4}$ Dental \\ Research Center, Research Institute of \\ Dental Sciences, Dental School, Shahid \\ Beheshti University of Medical Sciences, \\ Tehran, Iran
}

Introduction: The ventral tegmental area (VTA), as one of the classical components of the brain reward circuitry, shares large neural networks with the pain processing system. We previously showed the role of VTA dopamine receptors in modulation of lateral hypothalamus ( $\mathrm{LH}$ )-induced antinociception in acute pain conditions. However, considering the fact that the neural systems involved in the mediation of tonic pain are not the same as those that mediate phasic pain. In the present study, we aimed to examine the role of intra-VTA dopamine receptors in $\mathrm{LH}$-induced antinociceptive responses during tonic orofacial pain conditions.

Methods: Male Wistar rats weighing 230-250 g were implanted with two separate cannulae into the LH and VTA on the same side. Different solutions of carbachol $(62.5,125$ and 250 $\mathrm{nM}$ ), as a non-selective cholinergic receptor agonist that activates the $\mathrm{LH}$ projecting neurons, were microinjected into the LH. In the other groups, D1-like dopamine receptor antagonist, SCH-23390 $(0.25,1$ and $4 \mu \mathrm{g} / 03 \mu \mathrm{L}$ saline) or D2-like dopamine receptor antagonist, Sulpiride $(0.25,1$ and $4 \mu \mathrm{g} / 0.3 \mu \mathrm{L}$ DMSO 12\%) were microinjected into VTA, 5 min prior intra-LH carbachol $(250 \mathrm{nM})$, then subjected to orofacial formalin test. Intra-LH carbachol microinjection dose-dependently attenuated biphasic orofacial pain.

Results: Intra-VTA administration of SCH-23390 or Sulpiride dose-dependently decreased intra-LH carbachol-induced antinociception during both phases of orofacial formalin test with further effects in the late phase.

Discussion: The findings suggest that chemical stimulation of the LH by carbachol possibly activates the orexin projecting neurons and subsequently, the VTA dopaminergic neurons involved in the orofacial pain modulation. Detecting such neural circuitry offers an alternative approach in the development of more efficient therapies for such debilitating pain conditions.

Keywords: pain, D1-like dopamine receptor, D2-like dopamine receptor, ventral tegmental area, lateral hypothalamus, orofacial formalin test

\section{Introduction}

Orofacial pain is a prevalent and debilitating pain that may be particularly distressing due to the special psychological and emotional context of this body area. ${ }^{1}$ A formalin injection into the orofacial region is considered to be the only animal model of persistent pain in the trigeminal region. ${ }^{2}$ It has been demonstrated that carbachol as a non-selective cholinergic receptor agonist activates $20 \%$ of orexin

Azita Tehranchi

Dental Deformities Research Center

Dental Research Institute, School of

Dentistry, Shahid Beheshti University of

Medical Sciences, Tehran, Iran

Email Azitatehranchi@yahoo.com 
neurons through the M3 muscarinic receptors and subsequent activation of non-selective cation channels. ${ }^{3}$ Carbachol also inhibits a very small population of orexin neurons (1\%). ${ }^{3}$ Orexin neurons are localized exclusively in the lateral hypothalamus (LH) and project to almost all of the brain regions except the cerebellum. ${ }^{4,5}$ The rodent ventral tegmental area (VTA) contains both orexin receptors, orexin-1 (OX1) and orexin-2 (OX2) receptors ${ }^{6,7}$ with particularly high levels of OX2 receptor. ${ }^{7}$ Orexin potentially activates catecholaminergic neurons in the brainstem, including the VTA dopaminergic (DA) neurons and locus coeruleus noradrenergic neurons. ${ }^{6,8}$ Approximately $55 \%$ of the neurons located in VTA are dopaminergic neurons. ${ }^{9}$ Both DA neurons and GABAergic neurons of the VTA receive massive afferents from orexinergic neurons. ${ }^{10,11}$ In this regard, electrophysiological evidence indicated that orexin activates both DA and non-DA cells of the VTA via direct postsynaptic mechanisms. ${ }^{6}$ The involvement of VTA in the rewarding process has received much attention, and certain studies have demonstrated that the neural circuitry of reward also processes the motivational-affective dimension of pain and responds to aversive stimuli, such as noxious stimuli. ${ }^{12,13}$ This is because the rewarding system shares large neural networks with the pain processing system. ${ }^{14,15}$ Dopamine neurons located in the VTA region project to the prefrontal cortex, nucleus accumbens (NAc), basolateral amygdala, hippocampus, and other regions that participate in the modulation of pain 16-19.

Dopaminergic neurotransmission is mediated by five receptor subtypes (D1-D5) in the central nervous system (CNS). Among the five subtypes, the D1 and D5 dopamine receptors are classified as members of the D1-like family, while the D2-like dopamine receptor subfamily consists of D2, D3 and D4 dopamine receptors. These dopamine receptor subtypes have different affinity to various ligands. ${ }^{20}$ In our previous studies, we demonstrated that D1- and D2-like dopamine receptors within VTA and NAc are involved in the reduction of analgesia induced by chemical stimulation of $\mathrm{LH}$ in the tail-flick test as a model of acute pain. ${ }^{21,22}$ Pain assays in rodent studies revealed that the DA system has a more potent role in tonic pain, such as the formalin or writhing test as apposed to brief phasic pain stimuli, such as tail-flick or hot plate tests. ${ }^{23}$ These findings suggest that the neural systems involved in the mediation of tonic pain are not exactly the same as those that mediate phasic pain. Accordingly, in the current study, we induced orofacial pain in rats and assessed whether D1- and D2-like dopamine receptors within the VTA participate in antinociception are induced by LH chemical stimulation. In other words, the aim of this study was to suggest the LH-VTA neural circuitry in which LH participates in orofacial pain modulation.

\section{Materials and Methods Experimental Design}

In this study, rats were assigned to two separate control groups including normal saline and formalin control groups (Table 1). Among these, formalin group received $50 \mu \mathrm{L}$ formalin into upper lip and normal saline-control group received $50 \mu \mathrm{L}$ saline into upper lip, then returned to the plexiglass box for assessing animal's pain-related behaviors. To evaluate the effect of chemical stimulation of LH on pain modulation, three different solutions of carbachol $(62.5,125$ and $250 \mathrm{nM}$; CAR/Control) or it s vehicle (saline; SAL/Control) were microinjected into the LH of rats and subjected to orofacial formalin test. To evaluate the effect of D1- or D2-like dopamine receptor antagonist on antinociception induced by carbachol injections, $\mathrm{SCH}-23390(0.25,1$ or $4 \mu \mathrm{g} / 0.3 \mu \mathrm{L}$ saline in each group; $\mathrm{SCH} / \mathrm{CAR})$ or Sulpiride $(0.25,1$ or $4 \mu \mathrm{g} /$ $0.3 \mu \mathrm{L}$ DMSO $12 \%$ in each group; SUL/CAR) were microinjected, respectively, in the VTA, 5 min prior intraLH microinjection of carbachol $(250 \mathrm{nM})$. Saline is solvent of SCH-23390 and DMSO is solvent of Sulpiride. We used these vehicles for evaluation of the effect of injection volume and to compare their effects with respective drugs. Rats were then subjected to orofacial formalin test. Additionally, to investigate the effect of D1 or D2-like dopamine receptor antagonist alone on the nociceptive behaviors, animals received the maximum dose of SCH-23390 (4 $\mu \mathrm{g} / 0.3 \mu \mathrm{L}$ saline; $\mathrm{SCH} /$ Saline $)$ or Sulpiride $(4 \mu \mathrm{g} / 0.3 \mu \mathrm{L}$ DMSO $12 \%$; SUL/DMSO) respectively, into the VTA 5 min prior microinjection of intra-LH saline $(0.3 \mu \mathrm{L})$ and subjected to orofacial formalin test (Table 1). In this study, the experimenter was blind to treatment condition and protocol.

\section{Animals}

In this study, the ninety-one adult male albino Wistar rats weighing 230-250 g were purchased from Pasteur Institute (Tehran, Iran). The animals were randomly chosen and assigned in different experimental groups. Animals were kept in controlled temperature $\left(22 \pm 2^{\circ} \mathrm{C}\right)$, humidity $(47 \%)$, and 12-hour light/dark cycle with free access to food and 
Table I A Table Depicting All Control and Experimental Groups in the Study

\begin{tabular}{|c|c|c|c|c|}
\hline Group Names & & $\begin{array}{l}\text { Microinjection into the Lateral } \\
\text { Hypothalamus ( } 0.5 \mu \mathrm{L} / \mathrm{rat})\end{array}$ & $\begin{array}{l}\text { Microinjection into the Ventral } \\
\text { Tegmental Area }(0.3 \mu \mathrm{L} / \mathrm{rat})\end{array}$ & Surgery \\
\hline Intact & \multirow{14}{*}{$\begin{array}{l}\text { Subcutaneous injection of } 50 \mu \mathrm{L} \\
\text { formalin } 1 \% \text { into the upper lip }\end{array}$} & - & - & - \\
\hline Sham operated & & - & - & \multirow{13}{*}{$\begin{array}{l}\text { Surgery and recovery } \\
\text { periods ( } 5 \text { to } 7 \text { days) }\end{array}$} \\
\hline $\begin{array}{l}\text { Saline-control } \\
\text { (SAL/Control) }\end{array}$ & & Saline & - & \\
\hline Carbachol (CAR) & & Carbachol (250 nM) & - & \\
\hline $\begin{array}{l}\text { Vehicles } \\
\text { (VEHs) }\end{array}$ & & Saline & Saline or DMSO I2\% & \\
\hline $\begin{array}{l}\text { Carbachol-control groups } \\
\text { (CAR/Control) }\end{array}$ & & Carbachol (250 nM) & Saline or DMSO I $2 \%$ & \\
\hline \multirow{4}{*}{$\begin{array}{l}\mathrm{SCH} 23390 \text {-treated } \\
\text { groups } \\
\text { (SCH/CAR) } \\
\text { and (SCH/Saline) }\end{array}$} & & Carbachol $(250$ nM) & $\mathrm{SCH} 23390$ (0.5 $\mu \mathrm{g})$ & \\
\hline & & Carbachol $(250 \mathrm{nM})$ & $\mathrm{SCH} 23390(\mathrm{I} \mu \mathrm{g})$ & \\
\hline & & Carbachol $(250 \mathrm{nM})$ & $\mathrm{SCH} 23390(4 \mu \mathrm{g})$ & \\
\hline & & Saline & $\mathrm{SCH} 23390(4 \mu \mathrm{g})$ & \\
\hline \multirow{4}{*}{$\begin{array}{l}\text { Sulpiride-treated groups } \\
\text { (SUL/CAR) } \\
\text { and (SUL/DMSO) }\end{array}$} & & Carbachol (250 nM) & Sulpiride $(0.5 \mu \mathrm{g})$ & \\
\hline & & Carbachol (250 nM) & Sulpiride $(I \mu g)$ & \\
\hline & & Carbachol $(250 \mathrm{nM})$ & Sulpiride $(4 \mu g)$ & \\
\hline & & DMSO I2\% & Sulpiride $(4 \mu \mathrm{g})$ & \\
\hline
\end{tabular}

water during the whole period of experiments. All experiments were carried out by following the guidelines outlined in National Institutes of Health Guide for the Care and Use of Laboratory Animals (NIH Publication No. 80-23, revised 1996) and were confirmed by the Research and Ethics Committee of Shahid Beheshti University of Medical Sciences, Tehran, Iran (IR.SBMU.PHNS.REC.1397.031).

\section{Surgical Preparation}

Animals were anesthetized with an intraperitoneal injection of xylazine $2 \%(10 \mathrm{mg} / \mathrm{kg})$ and ketamine $10 \%$ $(100 \mathrm{mg} / \mathrm{kg})$ mixture and were placed in a stereotaxic apparatus (Stoelting, USA). Two stainless steel guide cannulae (23-gauge) were unilaterally inserted $1 \mathrm{~mm}$ above the LH and VTA. According to the Paxinos and Watson rat brain atlas, ${ }^{24}$ the coordinate for the LH was AP $=2.65 \pm$ $0.15 \mathrm{~mm}$ caudal to the bregma, Lat $= \pm 1.3 \mathrm{~mm}$ lateral to the midline and DV $=8.6 \mathrm{~mm}$ ventral from the skull surface, and for the VTA: AP $=4.8 \pm 0.15 \mathrm{~mm}$ caudal to the bregma, Lat $= \pm 0.8 \mathrm{~mm}$ lateral to the midline and DV $=8.3 \mathrm{~mm}$ ventral from the skull surface. Guide cannulae were then anchored to the skull surface using two stainless steel screws and dental acrylic cement. After surgery and before the initiation of behavioral experiments, animals were allowed to recover for 5-7 days.

\section{Drugs and Drug Administration}

Carbachol as a non-selective cholinergic receptor agonist (Carbamylcholine chloride; Sigma-Aldrich, St. Louis, Missouri, USA) was dissolved in sterile normal saline. D1-like dopamine receptor antagonist, SCH-23390, (R)-(+)-7-Chloro-8-hydroxy-3-methyl-1-phenyl-2, 3, 4, 5-tetrahydro-1H-3-benzazepine hydrochloride (Tocris Bioscience, Bristol, UK) was dissolved in sterile normal saline. D2-like dopamine receptor antagonist, Sulpiride, (S)-5-aminosulfonylN- [(1- ethyl-2 pyrrolidinyl) methyl]-2-methoxybenzamide (Tocris Bioscience, Bristol, UK) was dissolved in dimethyl sulfoxide (DMSO 12\%), Sigma-Aldrich, Germany. Formalin $2.5 \%$ was prepared by diluting $37 \%$ formaldehyde (Merck, Germany) with sterile physiological saline (0.9\%). All drugs or vehicle solutions were freshly prepared on the day of the experiment and infused slowly over $60 \mathrm{~s}$. All microinjections were conducted in freely moving animals via a stainless-steel injector (30-gauge needle; $1 \mathrm{~mm}$ longer than guide cannula) 
which was connected to a $1-\mu \mathrm{L}$ Hamilton syringe via a polyethylene tube (PE-20).

\section{Orofacial Formalin Test}

The orofacial formalin test was conducted using a plexiglass box $(30 \times 30 \times 30 \mathrm{~cm})$ with a mirror angled at $45^{\circ}$ below the surface of the box to observe the nociceptive behaviors of rats. ${ }^{2}$ Before to test initiation, an acclimation period of about $30 \mathrm{~min}$ was considered to allow animals to be stabilized in a new environment. Animals were subcutaneously injected with $50 \mu \mathrm{L}$ of $1 \%$ formalin into the upper lip just lateral to the nose using a 29-gauge injection needle. Formalin was injected into the upper lip, ipsilateral to the cannula placement into the rats' brain. Rats then immediately returned to the box and the amount of time that rats spent face rubbing with the ipsilateral paw was measured and considered as the index of nociception. In our experiments, we divided the recording time into 15 blocks of 3 min for a time-course analysis. Subcutaneous formalin injection induces biphasic nociceptive responses. Face rubbing activity measured between 0 and $3 \mathrm{~min}$ after subcutaneous formalin injection, considered as the first (early or acute) phase and those were measured between 15 and 33 min after formalin injection considered as the second (late or chronic) phase.

\section{Histological Verification}

Immediately after completion of the experiments, animals were deeply anesthetized with an intraperitoneal injection of ketamine and xylazine and the following perfusion with $0.9 \%$ normal saline and $10 \%$ formaldehyde solution, rats were then sacrificed, and their brains were carefully removed. Transverse brain sections with $50-\mu \mathrm{m}$ thickness were prepared and the location of the guide cannula tips was identified using the Paxinos and Watson rat brain atlas. ${ }^{24}$ Only the animals with correct cannulae placements were chosen for final data analysis (Figure 1).

\section{Data Analysis}

The obtained pain scores were expressed as mean \pm SEM (standard error of mean). Data analyses were performed by commercially available software GraphPad Prism ${ }^{\circledR}$ 6.0. The repeated measures two-way analysis of variance (ANOVA) followed by Bonferroni's post-hoc test was used to assess the effects of time and treatment (formalin injection) on the nociceptive scores (3-min blocks during a 45-min period; Figure 2A). To evaluate the carbachol dose-response, we used one-way ANOVA followed by
Dunnett's comparison tests and three different doses of carbachol were compared with saline as a vehicle (Figure 2B). It is also noted to evaluate the face rubbing time during both early and late phases separately, oneway ANOVA followed by Newman-Keuls multiple comparison tests were conducted to compare all groups with each other (Figure 3A and Figure 4A). Furthermore, to estimate the effective dose $50 \%$ (ED50), the best fitted line to represent the data on scatter plot was drawn and the estimated ED50 values were mathematically calculated based on three different doses of SCH-23390 or Sulpiride $(0.25,1,4 \mathrm{nM})$. In this study, the effect size was also calculated separately for early and late phases by dividing mean difference between the experimental and control groups by the standard deviation of the population from which the different treatment groups were taken. $\mathrm{P}<0.05$ was considered statistically significant.

\section{Results}

\section{Effect of Chemical Stimulation of $\mathrm{LH}$ Using Carbachol Microinjection on the Formalin-Induced Orofacial Nociception}

The time course of face rubbing as the nociceptive responses following injection of formalin or normal saline $(50 \mu \mathrm{L})$ into the orofacial region is presented in Figure 2A. Repeated measures two-way analysis of variance (ANOVA) followed by Bonferroni's post-hoc test was used to assess the effects of time and treatment (formalin injection) on the nociceptive scores (3-min blocks during a 45 -min period treatment effect: $F(1120)=657.4$, $\mathrm{P}<0.0001$; time effect: $\mathrm{F}(14,120)=17,65 \mathrm{P}<0.0001$; treatment and time interaction: $\mathrm{F}(14,120)=16.3, \mathrm{P}<0.0001]$.

Following injection of formalin into the upper lip, a biphasic pattern was observed while there were no significant differences in face rubbing time spent among several consecutive time points in normal saline-treated animals. As it has been shown in Figure 2B, one-way ANOVA followed by Dunnett's multiple comparison demonstrated that intra-LH carbachol microinjection (125 or $250 \mathrm{nM}$ ) dose-dependently decreased the face rubbing time during the first $[\mathrm{F}(3,29)=7.752, \mathrm{P}=0.0007$; left panel $]$ and second $[\mathrm{F}(3,29)=41.48, \mathrm{P}<0.0001$; right panel] phases of orofacial formalin test. The low concentration of carbachol $(62.5 \mathrm{nM})$ had no significant effect on face rubbing time during both phases of formalin nociception. 

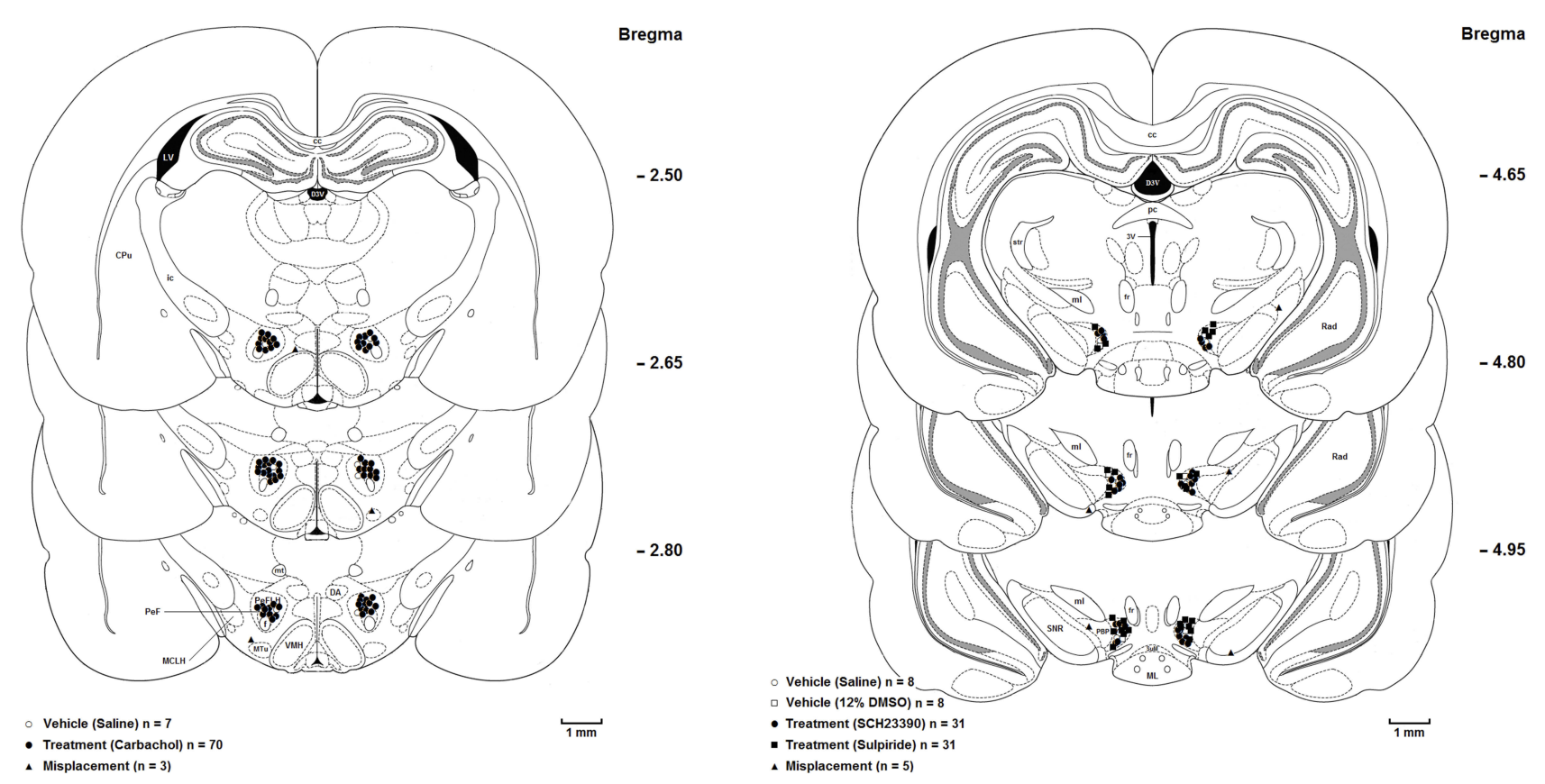

Figure I Coronal brain sections show the microinjection sites in the (left panel) lateral hypothalamus (०Saline; $\bullet$ Carbachol; $\boldsymbol{\Delta}$ Misplacement), and (right panel) ventral tegmental area (०Saline; 口DMSO; •SCH-23390; -Sulpiride; $\boldsymbol{\Delta}$ Misplacement).

Abbreviations: D3V, dorsal $3^{\text {rd }}$ ventricle; LV, lateral ventricle; CPu, caudate putamen (striatum); ic, internal capsule; cc, corpus callosum; DA, dorsal hypothalamic area; $\mathrm{CPu}$, caudate putamen (striatum); D3V, dorsal $3^{\text {rd }}$ ventricle; DA, dorsal hypothalamic area; mt, mammillothalamic tract; PeF, perifornical nucleus; PeFLH, perifornical part of lateral hypothalamus; MTu, medial tuberal nucleus; f, fornix; VMH, ventromedial hypothalamic nucleus; pc, posterior commissure; $3 \mathrm{~V}$, $3^{\text {rd }}$ ventricle; mL, medial lemniscus; Rad, radiatum layer of the hippocampus; fr, fasciculus retroflexus; SNR, substantia nigra, reticular part; str, superior thalamic radiation; VTA, ventral tegmental area; ML, medial mammillary nucleus, lateral part; PBP, parabrachial pigmented nucleus of the VTA; SuM, supramammillary nucleus; MCLH, magnocellular nucleus of the lateral hypothalamus; scale bar $=1 \mathrm{~mm}$.

\section{Effects of Intra-VTA Administration of DI-Like Dopamine Receptor Antagonist, $\mathrm{SCH}-23390$ on the Antinociception \\ Induced by Intra-LH Microinjection of Carbachol}

Our results showed that intra-VTA administration of D1-like dopamine receptor antagonist, SCH-23390, could significantly increase face rubbing activity during early $[\mathrm{F}(3,30)=5.195$, $\mathrm{P}=0.0058$; Figure $3 \mathrm{~A}$, left panel] and late $\mathrm{F}(3,30)=42.35$, $\mathrm{P}<0.0001$; Figure $3 \mathrm{~A}$, right panel] phases of orofacial formalin nociception compared to saline-carbachol group. As demonstrated in Figure 3A, both $1 \mu \mathrm{g}$ and $4 \mu \mathrm{g}$ solutions of SCH-23390 were able to decrease antinociceptive effects of carbachol $(250 \mathrm{nM})$ in both phases of orofacial formalin test. In addition, unpaired Student's $t$-test demonstrated that, $4 \mu \mathrm{g}$ solution of SCH-23390 could completely block the antinociception of carbachol, so that there was no difference between $\mathrm{SCH} / \mathrm{CAR}$ and $\mathrm{SCH} / \mathrm{Saline}$ groups in both early [ $\mathrm{t}(13)=$ $0.4259, \mathrm{p}=0.6771]$ and late $[\mathrm{t}(13)=0.4259, \mathrm{p}=0.677$, $p=0.4363]$ phases of the orofacial formalin test. The lowest concentration of SCH-23390 $(0.25 \mu \mathrm{g})$ had no significant effect on face rubbing time compared to the saline-carbachol group during both early and late phases of formalin-induced orofacial nociception. Moreover, Eta-squared as an estimated measure of effect size during the early phase $(\eta 2=0.37)$ was smaller than the late phase $(\eta 2=0.82)$ which represents the more prominent role of SCH-23390 in the elimination of intraLH carbachol-induced antinociception in late phase in comparison with the early phase. Moreover, as it has been depicted in Figure 3B, comparison of the effective dose of SCH-23390 in the elimination of intra-LH carbachol-induced antinociception between the early and late phases of orofacial formalin test showed that the antinociceptive effect of carbachol was reversed by a lower dose of SCH-23390 in the late phase $(E D 50=0.33)$ than the early phase $(E D 50=1.78)$ of orofacial formalin test.

\section{Effects of Intra-VTA Administration of D2-Like Dopamine Receptor Antagonist,} Sulpiride on the Antinociception Induced by Intra-LH Microinjection of Carbachol

According to our results, intra-VTA administration of D2like dopamine receptor antagonist, Sulpiride could significantly decrease carbachol-induced antinociception during 


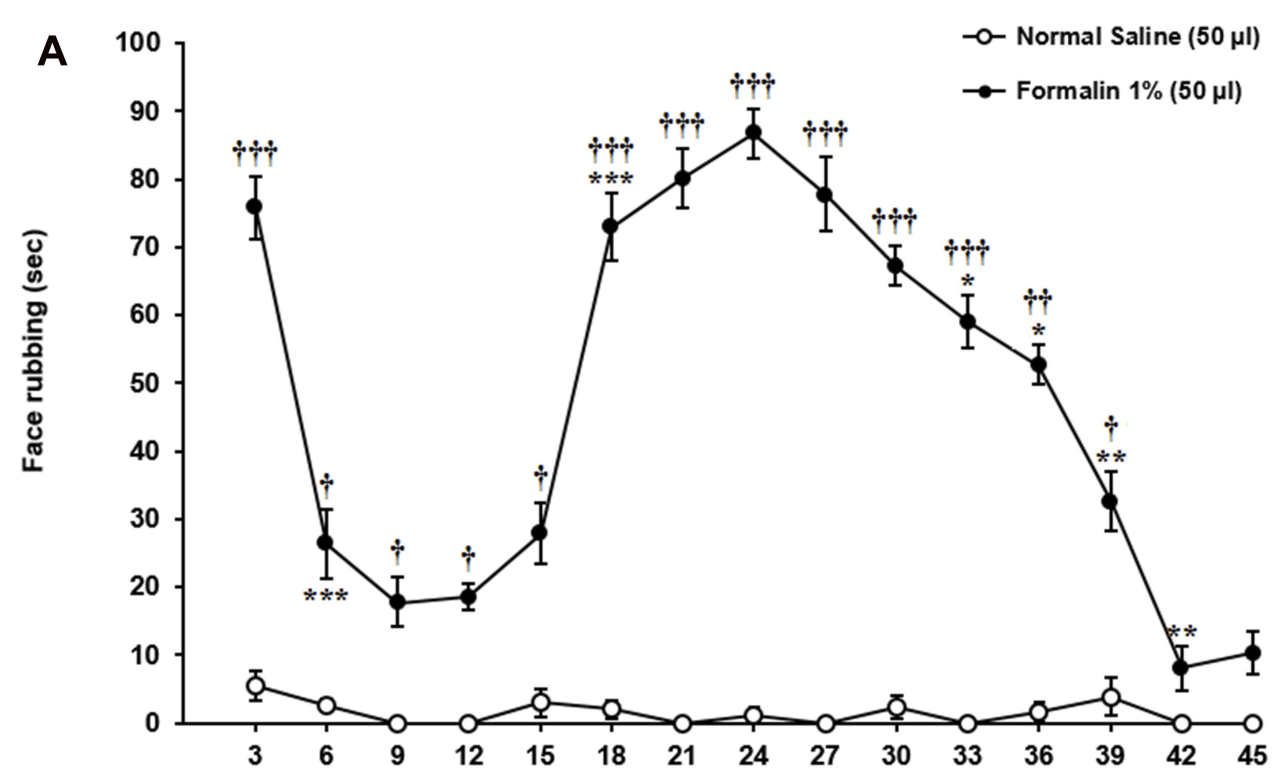

Time after formalin injection (min)

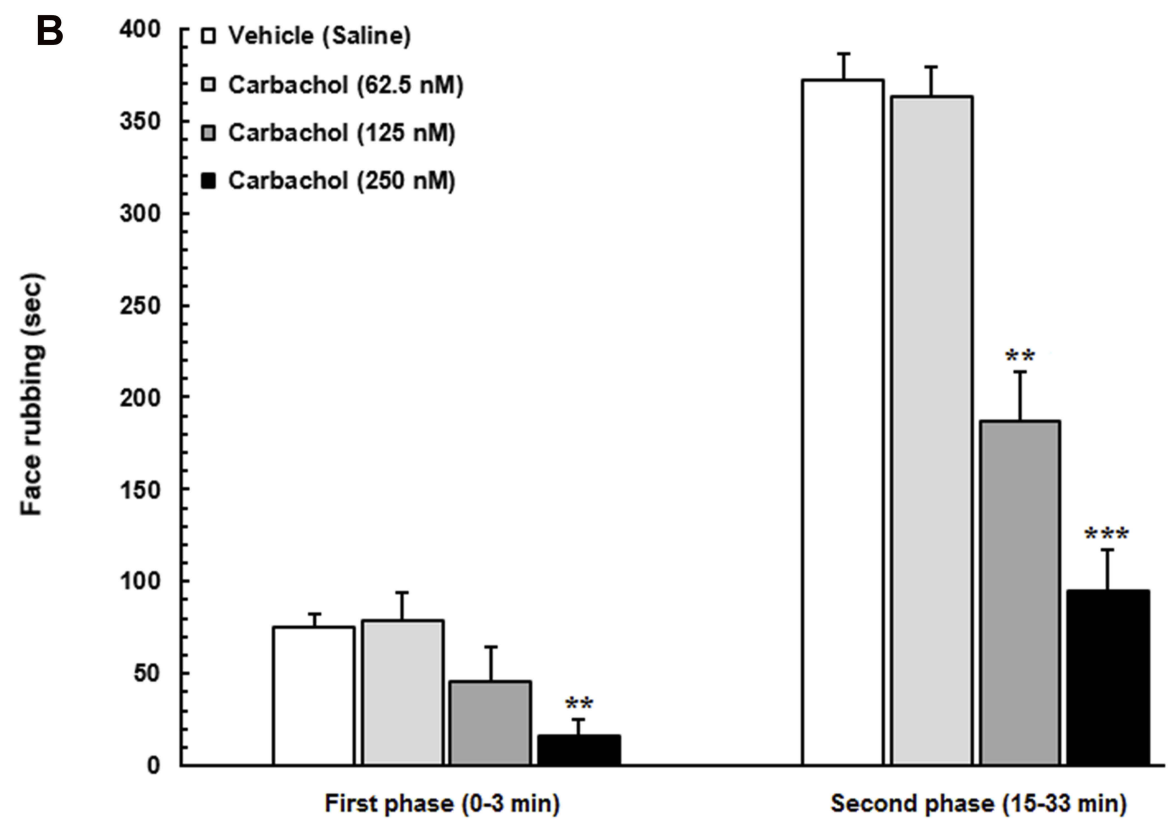

Figure 2 (A) The time course of face rubbing as the nociceptive responses immediately after subcutaneous injection of I\% formalin or normal saline into the orofacial region. Following formalin injection into the upper lip a significant increase in face rubbing time spent compared to respective 3-min block in normal saline group was observed. (B) The effect of microinjection of different solutions of carbachol into the LH on formalin-induced orofacial nociception. Intra-LH microinjection of carbachol $(62.5,125$ and $250 \mathrm{nM} / \mathrm{rat})$ attenuated face rubbing time spent (sec) during both phases of formalin orofacial nociception in a dose-dependent manner. Each point represents

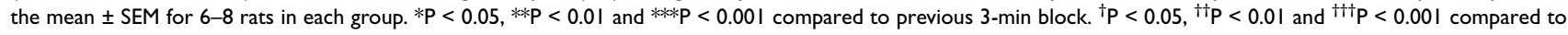
respective 3 -min block in normal saline group. $* * \mathrm{P}<0.01$ and $* * * \mathrm{P}<0.001$ compared to vehicle (Saline) group.

early $[\mathrm{F}(3,31)=7.614, \mathrm{P}=0.0007$; Figure $4 \mathrm{~A}$, left panel $]$ and late $[\mathrm{F}(3,31)=31.57, \mathrm{P}<0.0001$; Figure $4 \mathrm{~A}$, right panel $]$ phases of orofacial formalin nociception compared to salinecarbachol group. As it has been depicted in Figure 4A, the lowest concentration of Sulpiride $(0.25 \mu \mathrm{g})$ had no significant effect on face rubbing time compared to the saline-carbachol group while both $1 \mu \mathrm{g}$ and $4 \mu \mathrm{g}$ solutions of Sulpiride dosedependently decreased antinociceptive effects of carbachol $(250 \mathrm{nM})$ in both phases of orofacial formalin nociception. Additionally, unpaired Student's $t$-test demonstrated that 


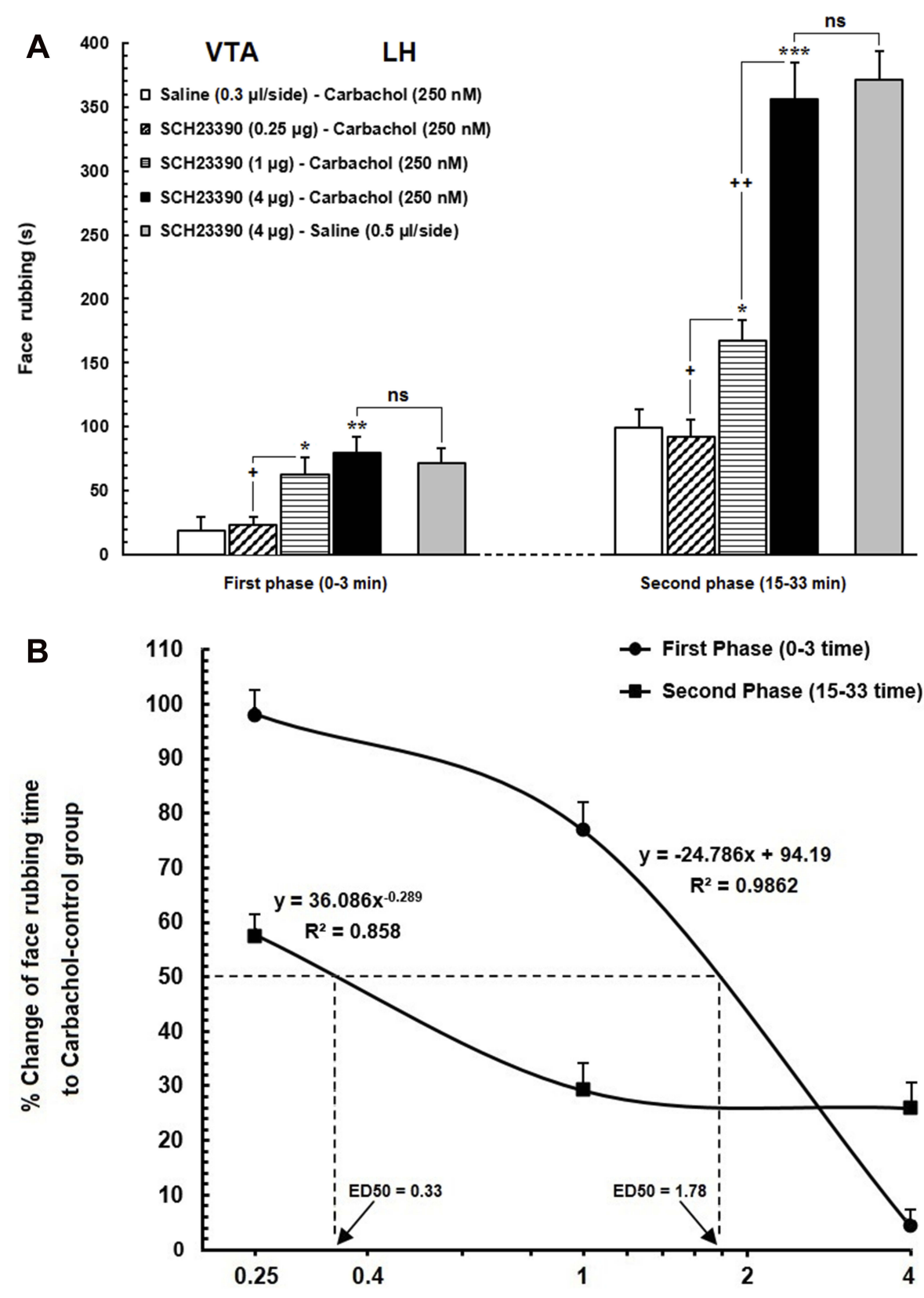

Intra-VTA administration of SCH23390 ( $\mu \mathrm{g} / 0.3 \mu \mathrm{l}$ Saline $)$

Intra-LH Carbachol $(250 \mathrm{nM} / 0.5 \mu \mathrm{l}$ saline $)$

Figure 3 (A) Effect of intra-VTA administration of $\mathrm{SCH} 23390$ (DI-like dopamine receptor antagonist) on the antinociception induced by chemical stimulation of $\mathrm{LH}$ using carbachol. Intra-VTA administration of SCH $23390(0.25, \mathrm{I}$ and $4 \mu \mathrm{g} / 0.3 \mu \mathrm{L}$ saline) significantly attenuated antinociception induced by intra-LH microinjection of carbachol $(250 \mathrm{nM} / \mathrm{rat})$ during both early and late phases of formalin-induced orofacial nociception. (B) A log dose-response curve of the effect of intra-VTA administration of different solutions of SCH-23390 $(0.25$, land $4 \mu \mathrm{g} / 0.3 \mu \mathrm{L}$ saline) on carbachol-induced antinociception during the early compared to that of late phase of formalin-induced orofacial nociception. The effective dose (ED50) of SCH-23390 in the late phase $(0.33 \mu \mathrm{g})$ was saliently less than that in the early phase $(1.78 \mu \mathrm{g})$. Each point represents the mean \pm SEM for 7-8 rats in each group. ${ }^{*} \mathrm{P}<0.05, * * \mathrm{P}<0.01$ and $* * * \mathrm{P}<0.001$ compared to saline-carbachol group. ${ }^{+} \mathrm{P}<0.05$ and ${ }^{++} \mathrm{P}<0.01$ compared to another group. Abbreviation: ns, non-significant.

$4 \mu \mathrm{g}$ solution of Sulpiride could completely block the antinociception induced by intra-LH carbachol microinjection, so that there was no difference between SUL/CAR and SUL/
Saline groups in both early [t $(13)=0.1335, \mathrm{p}=0.8959]$ and late $[\mathrm{t}(13)=0.8032, \mathrm{p}=0.4363]$ phases of orofacial formalin test. The effect size of Sulpiride during the early 

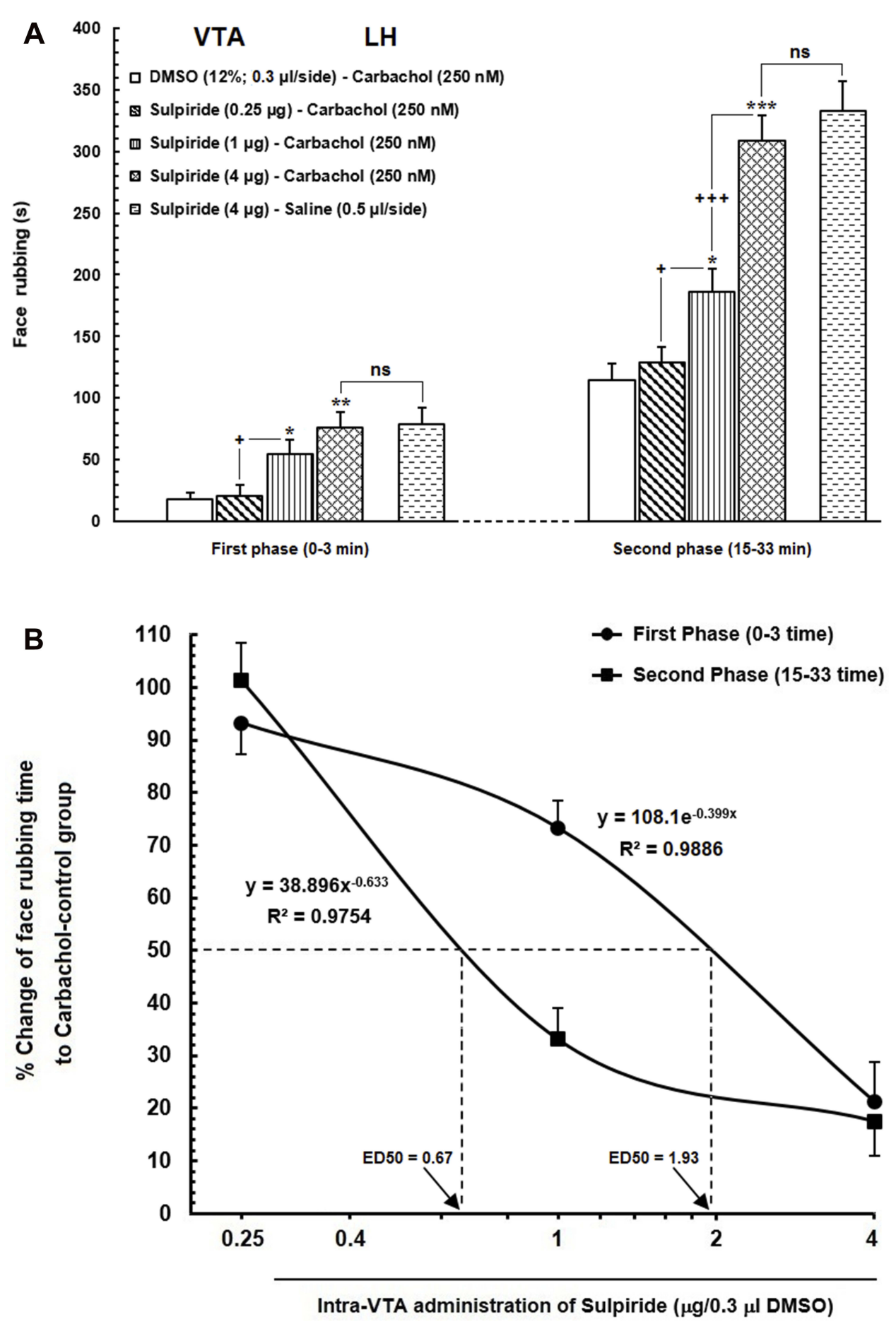

Intra-LH Carbachol (250 nM/0.5 $\mu$ l saline)

Figure 4 (A) Effect of intra-VTA injection of Sulpiride (D2-like dopamine receptor antagonist) on the LH stimulation-induced antinociception during orofacial formalin nociception. Intra-VTA administration of different doses of Sulpiride $(0.25,1$ and $4 \mu \mathrm{g} / 0.3 \mu \mathrm{L}$ DMSO I2\%) dose-dependently attenuated antinociception produced by intra$\mathrm{LH}$ microinjection of carbachol $(250 \mathrm{nM} / \mathrm{rat})$ during both early and late phases of formalin-induced orofacial nociception. (B) A log dose-response curve of the effect of intra-VTA administration of different solutions of Sulpiride $(0.25$, land $4 \mu \mathrm{g} / 0.3 \mu \mathrm{L}$ DMSO I $2 \%)$ on antinociception produced by carbachol during the early compared to that of late phase of formalin-induced orofacial nociception. The effective dose (ED50) of Sulpiride in the late phase $(0.67 \mu g)$ was obviously less than that in the early phase ( 1.93 $\mu \mathrm{g})$. Each point represents the mean \pm SEM for $7-8$ rats in each group. $* \mathrm{P}<0.05, * * \mathrm{P}<0.01$ and $* * * \mathrm{P}<0.001$ compared to DMSO-carbachol group ${ }^{+} \mathrm{P}<0.05$ and ${ }^{+++} \mathrm{P}<$ 0.00 I compared to another group.

Abbreviation: ns, non-significant. 
phase $(\eta 2=0.45)$ was smaller than the late phase $(0.77)$ indicating a more prominent role of Sulpiride in elimination of intra-LH carbachol-induced antinociception in late phase compared with the early phase. Figure $4 \mathrm{~B}$ depicts the log dose-response curve of changes in face rubbing time in Sulpiride injected groups compared to CAR/Control group. The log dose-response curve demonstrated that the antinociceptive effect of carbachol was reversed by a lower dose of Sulpiride in the late phase $(E D 50=0.67)$ than the early phase $(\mathrm{ED} 50=1.93)$ of orofacial formalin test.

\section{Discussion}

The results of the current study illustrated that D1- and D2-like dopamine receptors within the VTA are involved in antinociceptive effects induced by chemical stimulation of LH during both early and late phases of orofacial formalin test. The major findings of this study were as follows: (i) Chemical stimulation of LH using carbachol dose-dependently attenuated biphasic orofacial pain induced by formalin injections in the orofacial region of rats. (ii) Intra-VTA administration of D1-like dopamine receptor antagonist (SCH-23390) dose-dependently, decreased analgesia produced by intra-LH carbachol injections during both early and late phases of orofacial formalin test. (iii) Intra-VTA injection of D2-like dopamine receptor antagonist (Sulpiride), dose-dependently, attenuated analgesia produced by intra-LH injection of carbachol during both phases of orofacial formalin nociception. (iv) The roles of D1- and D2-like dopamine receptors of VTA in intra-LH carbachol-induced antinociception were noticeably more prominent in the late phase of orofacial formalin nociception in comparison with the early phase.

In the current study and other similar studies, it has been shown that chemical stimulation of LH using carbachol attenuates formalin nociception in a dose-dependent manner. ${ }^{25-29}$ Orexin neurons in the LH receive massive cholinergic input. So carbachol as a potent muscarinic cholinergic receptor agonist is able to increase the activity of these neurons. ${ }^{3}$ It has been established that neuroanatomical connections of OX neurons with some spinal and supraspinal areas, that are known to be part of descending pain modulatory circuitry, are involved in pain modulation. ${ }^{30}$ According to the result of the current study, VTA is involved in LH stimulation-induced antinociception. Although VTA plays a key role in the reward system, ${ }^{31}$ It has been confirmed that the reward system shares certain significant neural networks with the pain processing system. ${ }^{14,32}$ Accordingly, Morgan and Franklin, in 1990 reported that, lesions of VTA neurons abolished morphine-induced analgesia in an animal model of tonic pain. ${ }^{33}$ In this regard, it has been demonstrated that electrical stimulation of VTA after the nociceptive stimulus facilitates the analgesic process. ${ }^{34}$

We previously demonstrated that OX1and OX2 receptor functions in the VTA are essential for reward processing in the conditioned place preference model of rats. ${ }^{35}$ The rodent VTA contains both OX1 and OX2 receptors. ${ }^{6,36}$ Our results showed that the antinociception produced by LH stimulation is mediated by D1- and D2-like dopamine receptors of VTA. It has been reported that OX-A activates phospholipase $\mathrm{C}$ - and protein kinase $\mathrm{C}$-mediated $\mathrm{Ca}^{2+}$ signaling in DA neurons of the VTA and this effect may serve as the mechanism by which OX exerts its behavioral and psychostimulant effects. ${ }^{8}$ Neuroanatomical and electrophysiological evidences indicating the presence of OX1 and OX2 receptors in DA and nonDA neurons in VTA which demonstrates that both cell types of the VTA are potential targets for orexinergic actions. Both DA neurons and non-DA neurons, such as, GABAergic neurons of the VTA receive massive afferents from orexinergic neurons and are excited by these neurons. Electrophysiological evidence indicated that orexin activates both DA and non-DA cells of the VTA via direct postsynaptic mechanisms. ${ }^{6}$ Dopamine neurons of the VTA region project to the prefrontal cortex, NAc, basolateral amygdala, hippocampus, and other regions that participate in the modulation of pain. ${ }^{16-19}$ It has been proven that LH orexin projections to VTA increase firing in NAc projecting dopamine neurons. ${ }^{37}$ Dopaminergic VTA projections to NAc have been largely associated with the pain modulatory role of LH's orexinergic neurons. ${ }^{16,38}$ On the other hand, the results of a study demonstrated thatchronic increase of GABAergic neuronal activity in VTA region suppresses VTA dopaminergic neuronal activity which is responsible for negative affective aspects of neuropathic pain. ${ }^{39}$ Therefore, it seems that the both of DA cells and non-DA cells of VTA are responsible for the pain modulatory role of $\mathrm{LH}$, but finding the exact contribution of these neurons requires more extensive studies. In this respect, the results of our recent study demonstrated that orexin receptors within the NAc participate in pain modulatory role of the LH in both early and late phases of orofacial formalin test. ${ }^{40}$ In addition, the results of an animal study demonstrated that the administration of dopamine receptor antagonists into the NAc led to attenuation of antinociception produced by intra-VTA injection of morphine or Substance P. ${ }^{23}$ Therefore, it seems that antinociceptive effect of VTA dopaminergic system in part is associated with VTA projecting neurons to the NAc. Lapirot et al in 2011 documented that D2-like dopamine receptors are predominantly located 
within superficial medullary dorsal horn adjacent to trigeminal nociceptive fibers and activating these receptors inhibits both formalin and capsaicin-evoked pain behavior. Activation of D2-like dopamine receptors in this area also inhibits C-fiberevoked action potential firing of trigeminal wide dynamic range (WDR) neuron. ${ }^{41}$ In the current study, we demonstrated that D1- and D2-like dopamine receptors within the VTA are involved in the pain modulatory role of $\mathrm{LH}$ stimulation in a model of tonic orofacial pain. Additionally, we previously reported in two separate studies that D1- and D2-like dopamine receptors within VTA and NAc are potentially involved in LHinduced analgesia in the tail-flick test as a model of acute phasic pain. $^{21,22}$ It has been found that dopamine is differentially involved in the mediation of antinociception in phasic and tonic pain conditions. Pain assays in rodent studies revealed that the DA system has a more potent role in tonic pain, such as that shown in the formalin or writhing test than brief phasic pain stimuli, shown in the tail flick or hot plate tests. ${ }^{23}$ However, the precise mechanisms served by the DA system to alleviate both phasic and tonic pain should be more extensively evaluated.

A typical behavioral response to subcutaneous formalin injection into the orofacial region is biphasic pain response, a short-lasting early phase and a prolonged late phase. ${ }^{42,43}$ In the present study, the role of D1- and D2-like dopamine receptors of VTA in intra-LH carbachol-induced antinociception was noticeably more prominent in the late phase of orofacial formalin nociception in comparison with the early phase. This discrepancy might stem from the different mechanisms involved in early and late phases of formalin nociception. ${ }^{44}$ Formalin injection into orofacial receptive field evoked activity in A $\delta$ and $\mathrm{C}$ fibers as well as spinal and trigeminal nociceptive neurons and provokes biphasic orofacial pain and concentration-dependent tissue damage. ${ }^{2}$ The first phase of formalin nociception is attributed to the activation of primary afferent neurons and induced by the activation of the C-fibers. This is while the second phase seems to be dependent on the inflammatory reaction in the peripheral tissue and combination of functional changes in the dorsal horn which leads to peripheral and central sensitization of primary and secondary trigeminal nociceptive neurons. ${ }^{2,43,45}$

In this regard, it has been reported that the action of some analgesics is different in the early and the late phase of formalin nociception. ${ }^{46,47}$

In this study, we tried to focus on the role of D1- and D2like dopamine receptors within the VTA in antinociception induced by LH stimulation using carbachol. However, this study has some limitations that should take into consideration for interpreting the data. First of all, the excitation of $\mathrm{OX}$ neurons in the LH by carbachol could be confirmed using c-fos immunoreactivity method. Secondly, anterograde tracing is also a valuable research method, which could be used to trace the dopaminergic axonal projections to the VTA. Thirdly, the contribution of each D1-/D2-like dopamine receptors of VTA alone, by antinociceptive effects of LH should be evaluated. Taken together, we suggest that chemical stimulation of the LH by using carbachol activates the VTA dopaminergic neurons possibly via activation of $\mathrm{LH}$ orexin projecting neurons, and so, it participates as a neural circuitry that modulates tonic orofacial pain. The contribution of this neural circuitry to orofacial pain perception and modulation will help us to understand tonic pain pathophysiology. Moreover, understanding the critical role of certain brain regions such as LH or VTA in pain modulation as well as, the mechanisms in which these areas participate in analgesia offer an alternative approach to the development of more efficient pain therapies with focusing on these brain areas.

\section{Acknowledgments}

The authors would like to thank the Dental Research Center, School of Dentistry, Shahid Beheshti University of Medical Sciences, and also the Neuroscience Research Center, Shahid Beheshti University of Medical Sciences, Tehran, Iran, for their cooperation in carrying out this study.

\section{Disclosure}

The authors report no conflicts of interest in this work.

\section{References}

1. Krzyzanowska A, Avendaño C. Behavioral testing in rodent models of orofacial neuropathic and inflammatory pain. Brain Behav. 2012;2 (5):678-697. doi:10.1002/brb3.85

2. Raboisson P, Dallel R. The orofacial formalin test. Neurosci Biobehav Rev. 2004;28(2):219-226. doi:10.1016/j.neubiorev.2003.12.003

3. Ohno K, Hondo M, Sakurai T. Cholinergic regulation of orexin/hypocretin neurons through M3 muscarinic receptor in mice. $J$ Pharmacol Sci. 2008;106(3):485-491. doi:10.1254/jphs.FP0071986

4. Nambu T, Sakurai T, Mizukami K, et al. Distribution of orexin neurons in the adult rat brain. Brain Res. 1999;827(1-2):243-260. doi:10.1016/ S0006-8993(99)01336-0

5. Peyron C, Tighe DK, Van Den Pol AN, et al. Neurons containing hypocretin (orexin) project to multiple neuronal systems. J Neurosci. 1998;18 (23):9996-10015. doi:10.1523/JNEUROSCI.18-23-09996.1998

6. Korotkova TM, Sergeeva OA, Eriksson KS, et al. Excitation of ventral tegmental area dopaminergic and nondopaminergic neurons by orexins/hypocretins. $J$ Neurosci. 2003;23(1):7-11. doi:10.1523/ JNEUROSCI.23-01-00007.2003

7. Lu X-Y, Bagnol D, Burke S, et al. Differential distribution and regulation of OX1 and OX2 orexin/hypocretin receptor messenger RNA in the brain upon fasting. Horm Behav. 2000;37(4):335-344. doi:10.1006/hbeh.2000.1584 
8. Uramura K, Funahashi H, Muroya S, et al. Orexin-a activates phospholipase $\mathrm{C}$-and protein kinase $\mathrm{C}$-mediated $\mathrm{Ca} 2+$ signaling in dopamine neurons of the ventral tegmental area. Neuroreport. 2001;12 (9):1885-1889. doi:10.1097/00001756-200107030-00024

9. Margolis EB, Lock H, Hjelmstad GO, et al. The ventral tegmental area revisited: is there an electrophysiological marker for dopaminergic neurons? J Physiol. 2006;577(3):907-924. doi:10.1113/ jphysiol.2006.117069

10. Fadel J, Deutch A. Anatomical substrates of orexin-dopamine interactions: lateral hypothalamic projections to the ventral tegmental area Neuroscience. $\quad$ 2002;111(2):379-387. doi:10.1016/S0306-4522(02) 00017-9

11. Balcita-Pedicino JJ, Sesack SR. Orexin axons in the rat ventral tegmental area synapse infrequently onto dopamine and $\gamma$-aminobutyric acid neurons. J Compar Neurol. 2007;503(5):668-684. doi:10.1002/cne.21420

12. Li A-L, Sibi JE, Yang X, et al. Stimulation of the ventral tegmental area increased nociceptive thresholds and decreased spinal dorsal horn neuronal activity in rat. Exp Brain Res. 2016;234 (6):1505-1514. doi:10.1007/s00221-016-4558-z

13. DosSantos MF, Moura B, DaSilva AF. Reward circuitry plasticity in pain perception and modulation. Front Pharmacol. 2017;8:790. doi:10.3389/fphar.2017.00790

14. Whalley K. Neural circuits: pain or pleasure? Nat Rev Neurosci. 2015;16(6):316. doi:10.1038/nrn3975

15. Namburi P, Beyeler A, Yorozu S, et al. A circuit mechanism for differentiating positive and negative associations. Nature. 2015;520 (7549):675. doi:10.1038/nature14366

16. Yazdi-Ravandi S, Razavi Y, Haghparast A, et al. Orexin A induced antinociception in the ventral tegmental area involves D1 and D2 receptors in the nucleus accumbens. Pharmacol Biochem Behav. 2014;126:1-6. doi:10.1016/j.pbb.2014.08.009

17. Lindvall O, Björklund A, Moore RY, et al. Mesencephalic dopamine neurons projecting to neocortex. Brain Res. 1974;81(2):325-331. doi:10.1016/0006-8993(74)90947-0

18. Watanabe M, Narita M, Hamada Y, et al. Activation of ventral tegmental area dopaminergic neurons reverses pathological allodynia resulting from nerve injury or bone cancer. Mol Pain. 2018;14:1744806918756406. doi:10.1177/1744806918756406

19. Swanson L. The projections of the ventral tegmental area and adjacent regions: a combined fluorescent retrograde tracer and immunofluorescence study in the rat. Brain Res Bull. 1982;9(1-6):321-353. doi:10.1016/0361-9230(82)90145-9

20. Wang Q, Mach RH, Luedtke RR, et al. Subtype selectivity of dopamine receptor ligands: insights from structure and ligand-based methods. J chem inf model. 2010;50(11):1970-1985.

21. Moradi M, Fatahi Z, Haghparast A. Blockade of D1-like dopamine receptors within the ventral tegmental area and nucleus accumbens attenuates antinociceptive responses induced by chemical stimulation of the lateral hypothalamus. Neurosci Lett. 2015;599:61-66. doi:10.1016/j.neulet.2015.05.047

22. Moradi M, Yazdanian M, Haghparast A. Role of dopamine D2-like receptors within the ventral tegmental area and nucleus accumbens in antinociception induced by lateral hypothalamus stimulation. Behav Brain Res. 2015;292:508-514. doi:10.1016/j.bbr. 2015.07.007

23. Altier N, Stewart J. The role of dopamine in the nucleus accumbens in analgesia. Life Sci. 1999;65(22):2269-2287. doi:10.1016/S00243205(99)00298-2

24. Paxinos G, Watson C. The Rat Brain in Stereotaxic Coordinates: Hard Cover Edition. Elsevier; 2006.

25. Ezzatpanah S, Babapour V, Sadeghi B, et al. Chemical stimulation of the lateral hypothalamus by carbachol attenuated the formalin-induced pain behaviors in rats. Pharmacol Biochem Behav. 2015;129:105-110. doi:10.1016/j.pbb.2014.12.012
26. Ezzatpanah S, Babapour V, Haghparast A. Differential contribution of orexin receptors within the ventral tegmental area to modulation of persistent inflammatory pain. Eur J Pain. 2016;20(7):1090-1101. doi:10.1002/ejp.833

27. Yazdi F, Jahangirvand M, Ezzatpanah S, et al. Role of orexin-2 receptors in the nucleus accumbens in antinociception induced by carbachol stimulation of the lateral hypothalamus in formalin test. Behav Pharmacol. 2016;27(5):431-438. doi:10.1097/FBP.000000 0000000216

28. Haghparast A, Shafiei I, Alizadeh A-M, et al. Blockade of the orexin receptors in the CA1 region of hippocampus decreased the lateral hypothalamic-induced antinociceptive responses in the model of orofacial formalin test in the rats. Peptides. 2018;99:217-222. doi:10.1016/j.peptides.2017.10.006

29. Shafiei I, Vatankhah M, Zarepour L, et al. Role of D1-and D2-like dopaminergic receptors in the nucleus accumbens in modulation of formalin-induced orofacial pain: involvement of lateral hypothalamus. Physiol Behav. 2018;188:25-31. doi:10.1016/j. physbeh.2018.01.020

30. Holden JE, Pizzi JA. Lateral hypothalamic-induced antinociception may be mediated by a substance $\mathrm{P}$ connection with the rostral ventromedial medulla. Brain Res. 2008;1214:40-49. doi:10.1016/j. brainres.2008.03.051

31. Schultz W, Dayan P, Montague PR. A neural substrate of prediction and reward. Science. 1997;275(5306):1593-1599. doi:10.1126/ science.275.5306.1593

32. Leknes S, Tracey I. A common neurobiology for pain and pleasure. Nat Rev Neurosci. 2008;9(4):314. doi:10.1038/nrn2333

33. Morgan MJ, Franklin KB. 6-Hydroxydopamine lesions of the ventral tegmentum abolish D-amphetamine and morphine analgesia in the formalin test but not in the tail flick test. Brain Res. 1990;519(1-2):144-149. doi:10.1016/0006-8993(90)90072-J

34. Sotres-Bayón F, Torres-López E, López-Ávila A, et al. Lesion and electrical stimulation of the ventral tegmental area modify persistent nociceptive behavior in the rat. Brain Res. 2001;898(2):342-349. doi:10.1016/S0006-8993(01)02213-2

35. Farahimanesh S, Zarrabian S, Haghparast A. Role of orexin receptors in the ventral tegmental area on acquisition and expression of morphine-induced conditioned place preference in the rats. Neuropeptides. 2017;66:45-51. doi:10.1016/j.npep.2017.08.003

36. Narita M, Nagumo Y, Hashimoto S, et al. Direct involvement of orexinergic systems in the activation of the mesolimbic dopamine pathway and related behaviors induced by morphine. J Neurosci. 2006;26(2):398-405. doi:10.1523/JNEUROSCI.2761-05.2006

37. Baimel C, Lau BK, Qiao M, et al. Projection-target-defined effects of orexin and dynorphin on VTA dopamine neurons. Cell Rep. 2017;18 (6):1346-1355. doi:10.1016/j.celrep.2017.01.030

38. Azhdari-Zarmehri H, Reisi Z, Vaziri A, et al. Involvement of orexin-2 receptors in the ventral tegmental area and nucleus accumbens in the antinociception induced by the lateral hypothalamus stimulation in rats. Peptides. 2013;47:94-98. doi:10.1016/j.peptides.2013.07.012

39. Ko MY, Jang EY, Lee JY, et al. The role of ventral tegmental area gamma-Aminobutyric acid in chronic neuropathic pain after spinal cord injury in rats. Jneurotrauma. 2018;35(15):1755-1764.

40. Haghparast A, Matini T, Rezaee L, et al. Involvement of orexinergic system within the nucleus accumbens in pain modulatory role of the lateral hypothalamus in orofacial pain model. Neurochem Res. 2020;45(4):851-859. doi:10.1007/s11064-020-02957-9

41. Lapirot O, Melin C, Modolo A, et al. Tonic and phasic descending dopaminergic controls of nociceptive transmission in the medullary dorsal horn. PAIN ${ }^{\circledR}$. 2011;152(8):1821-1831. doi:10.1016/j.pain.2011.03.030

42. Raboisson P, Bourdiol P, Dallel R, et al. Responses of trigeminal subnucleus oralis nociceptive neurones to subcutaneous formalin in the rat. Neurosci Lett. 1991;125(2):179-182. doi:10.1016/03043940(91)90022-L 
43. Shields SD, Cavanaugh DJ, Lee H, et al. Pain behavior in the formalin test persists after ablation of the great majority of C-fiber nociceptors. PAIN $^{\circledR}$. 2010;151(2):422-429. doi:10.1016/j.pain.2010.08.001

44. Wheeler-Aceto H, Porreca F, Cowan A. The rat paw formalin test: comparison of noxious agents. Pain. 1990;40(2):229-238. doi:10.1016/0304-3959(90)90073-M

45. Sessle BJ. Peripheral and Central Mechanisms of Orofacial Inflammatory Pain. International Review of Neurobiology. Elsevier; 2011:179-206.
46. Hunskaar S, Fasmer OB, Hole K. Formalin test in mice, a useful technique for evaluating mild analgesics. J Neurosci Methods. 1985;14(1):69-76. doi:10.1016/0165-0270(85)90116-5

47. Shibata M, Ohkubo T, Takahashi H, et al. Modified formalin test: characteristic biphasic pain response. pain. 1989;38(3):347-352. doi:10.1016/0304-3959(89)90222-4

\section{Publish your work in this journal}

The Journal of Pain Research is an international, peer reviewed, open access, online journal that welcomes laboratory and clinical findings in the fields of pain research and the prevention and management of pain. Original research, reviews, symposium reports, hypothesis formation and commentaries are all considered for publication. The manuscript management system is completely online and includes a very quick and fair peer-review system, which is all easy to use. Visit http:/ www.dovepress.com/testimonials.php to read real quotes from published authors. 